$\overline{\text { Original }}$

\title{
Studies on Pesticide Degradation Products in Pesticide Residue Analysis
}

\author{
(Received April 24, 1998) \\ Yumi Aкiyama, Naoki Yoshioka and Masahiko Tsujı \\ (Hyogo Prefectural Institute of Public Health: 2-1-29, Arata-cho, Hyogo-ku, \\ Kobe 652-0032, Japan)
}

\begin{abstract}
In order to apply the multiresidue screening method to degradation products of $N$ trihalomethylthio fungicides (captan, captafol, folpet, dichlofluanid, tolylfluanid) and oxidized organophosphorus insecticides generated during sample preparation or in plants, the recovery of sixteen of these degradation products and metabolites from 3 agricultural products was investigated. The recoveries ranged from 74 to $129 \%$, and these data suggest that the degradation products can be determined simultaneously with the parent pesticides by this method.

The degradation ratios of $5 \mathrm{~N}$-trihalomethylthio fungicides, demeton-S-methyl and isofenphos were examined during sample preparation from 5 agricultural products and during GC injection. Cabbage, spinach and pumpkin readily caused the degradation of $\mathrm{N}$ trihalomethylthio fungicides, and the degradation ratios of captan were 100,100 and $81 \%$, respectively. Decreases of the parent pesticides corresponded closely to the formation of the degradation products.
\end{abstract}

Key words: pesticide degradation products; multiresidue analysis; GC/MS; agricultural products; $N$-trihalomethylthio fungicide

\section{Introduction}

The number of regulated pesticides in the Food Sanitation Law ${ }^{11}$ has been increasing annually since 1993 . The pesticide multiresidue method is an efficient way to screen a large number of food samples. It is well known that $\mathrm{N}$-trihalomethylthio fungicides (captan, captafol, folpet, dichlofluanid, tolylfluanid) are degraded by chemical reaction with thiol groups (-SH) of the plant matrices during sample grinding ${ }^{2)}$, and demeton-S-methyl and isofenphos are oxidized to sulfone or oxon analogues ${ }^{3)}$. Some analytical modifications, such as addition of phosphoric acid ${ }^{4)}$ or hydrochloric acid ${ }^{5)}$, have been proposed to prevent such degradation. These degradation products are produced not only during the sample preparation step, but also in the plant itself after pesticide application. Several studies have been reported on the disappearance of pesticides during extraction pro- cedures ${ }^{* 1,2}$, but degradation products have not been well studied quantitatively*3.

Aiming at the simple and rapid screening of pesticide residues, we investigated the simultaneous determination of both parent pesticides and their degradation products. This paper reports the application of our previous findings ${ }^{6,7)}$ to degradation products produced during sample preparation, or in plants, and also reports the effect of matrices on the degradation

*1 Iwata, H., Arimura, Y., Matsuhira, Y., Imaizumi, N., Shibuya, T., Maekawa, Y.: Abstracts of the 70th Meeting of the Food Hygienic Society of Japan, p. 44 (1995. 10. Nagoya).

*2 Iwata, H., Arimura, Y., Matsuhira, Y., Imaizumi, N., Shibuya, T., Maekawa, Y.: Abstracts of the 71st Meeting of the Food Hygienic Society of Japan, p. 41 (1996. 5. Ibaraki).

*3 Iwahori, M., Imaizumi, N., Shibuya, T., Maekawa, Y.: Abstracts of the 65th Meeting of the Food Hygienic Society of Japan, p. 51 (1993. 5. Tokyo). 
of pesticides during sample preparation and GC injection.

\section{Materials and Methods}

\section{Food samples}

Brown rice, lemon, spinach, cabbage, pumpkin, and kiwi fruit were used in this study.

\section{Analytical standards}

Pesticides and their degradation products: Folpet, demeton-S-methyl, demeton-S-methylsulfone, isofenphos oxon, isoxathion oxon, parathion oxon, parathionmethyl oxon, malathion oxon, $N^{\prime}, N^{\prime}$-dimethyl- $N$-phenylsulfonyldiamide (degradation product of dichlofluanid), and $N^{\prime}, N^{\prime}$-dimethyl- $N$ - $p$-tolylsulfonyldiamide (degradation product of tolylfluanid) were purchased from Hayashi Pure Chemical Industries (Osaka, Japan), and captafol, captan, dichlofluanid, tolylfluanid, isofenphos, diazinon oxon, fenitrothion oxon, prothiofos oxon, EPN oxon, 2chlorobenzonitrile (degradation product of clofentezine), 4,4'-dichlorobenzophenone (degradation product of dicofol), 1,2,3,6-tetrahydrophthalimide (degradation product of captan and captafol), and phthalimide (degradation product of folpet) were from Wako Pure Chemical Industries (Osaka, Japan).

Standard solutions: Individual stock standard solutions $(250 \mu \mathrm{g} / \mathrm{mL})$ were prepared in acetone. Working solutions were prepared from stock solutions at $25 \mu \mathrm{g} / \mathrm{mL}$ with acetone. Mixed standard solutions for GC/MS analysis were freshly diluted with $n$-hexane-acetone $(4: 1)$ for parent pesticides and degradation products.

\section{Instrumentation}

Gas chromatography with mass-selective detection was performed on a Hewlett Packard HP 5890 Series II GC system with an HP5972 MSD system. The following analytical conditions were used: a 5\% phenyl-methyl silicone column (DB- $5 \mathrm{~ms}, 30 \mathrm{~m} \times 0.25 \mathrm{~mm}$ i.d., $0.10 \mu \mathrm{m}$ film thickness); initial oven temperature $80^{\circ} \mathrm{C}$, hold $3 \mathrm{~min}$, linear gradient $30^{\circ} \mathrm{C} / \mathrm{min}$ to $170^{\circ} \mathrm{C}$, hold $4 \mathrm{~min}$, then linear gradient $10^{\circ} \mathrm{C} / \mathrm{min}$ to $270^{\circ} \mathrm{C}$, hold 15 min; injector temperature $250^{\circ} \mathrm{C}$; interface temperature $280^{\circ} \mathrm{C}$; initial carrier gas $(\mathrm{He})$ pressure $30 \mathrm{psi}(4 \mathrm{~mL} / \mathrm{min})$, hold $1 \mathrm{~min}$, decrease immediately to $8 \mathrm{psi}$, keep constant flow $(0.9 \mathrm{~mL} / \mathrm{min})$; injection volume $4 \mu \mathrm{L}$ (splitless mode); purge off time $1 \mathrm{~min}$; ionization energy $70 \mathrm{eV}$. The pesti-
Sample $25 \mathrm{~g}$

$-\mathrm{CH}_{3} \mathrm{CN} 60 \mathrm{~mL}$
homogenize
filter

Filtrate

pass through ODS ( $1 \mathrm{~g}$ ) mini-column under slightly reduced pressure salting-out with $\mathrm{NaCl} 6 \mathrm{~g}$ at $\mathrm{pH} 7$ shake

$\mathrm{CH}_{3} \mathrm{CN}$ layer $36 \mathrm{~mL}$ (equal to sample $15 \mathrm{~g}$ ) dehydrate with $\mathrm{Na}_{2} \mathrm{SO}_{4}$ evap. to near dryness adj. to $3 \mathrm{~mL}$ with $n$-hexane-acetone $(1: 1)$

$2 \mathrm{~mL}$ aliquot

pass through PSA $(200 \mathrm{mg})$ mini-column

$-n$-hexane-acetone $(1: 1) 2 \mathrm{~mL} \times 3$

evap. to near dryness

adj. to $2 \mathrm{~mL}$ with $n$-hexane-acetone $(4: 1)$

Sample solution for GC/MS

Scheme 1. Sample preparation method for multipesticide residue analysis

cides were detected in the SCAN mode (50 450 amu, 1.8 scans $/ \mathrm{sec}$ ).

4. Recovery test for degradation products and metabolites

Twenty-five gram portions of chopped samples (lemon and spinach) and ground samples (brown rice) were fortified with $0.1 \mathrm{~mL}$ of mixed working solution $(25 \mu \mathrm{g} / \mathrm{mL}$ each of pesticide degradation products and metabolites). The fortified samples were analyzed as described previously ${ }^{7}$, that is, blended with acetonitrile, then cleaned up through ODS and PSA minicolumns (Scheme 1).

\section{Degradation during sample preparation}

Twenty-five gram portions of chopped or ground samples (cabbage, pumpkin, spinach, brown rice and kiwi fruit) were fortified with 0.2 $\mathrm{mL}$ of mixed working solution of parent pesticides $(25 \mu \mathrm{g} / \mathrm{mL}$ each of captan, folpet, dichlofluanid, tolylfluanid, demeton-S-methyl and isofenphos). Captafol was separately added to cabbage and pumpkin with $0.2 \mathrm{~mL}$ of working solution $(25 \mu \mathrm{g} / \mathrm{mL})$. The control was performed by making up the volume to $25 \mathrm{~mL}$ with purified water, without sample matrices. The samples were analyzed according to the procedure 

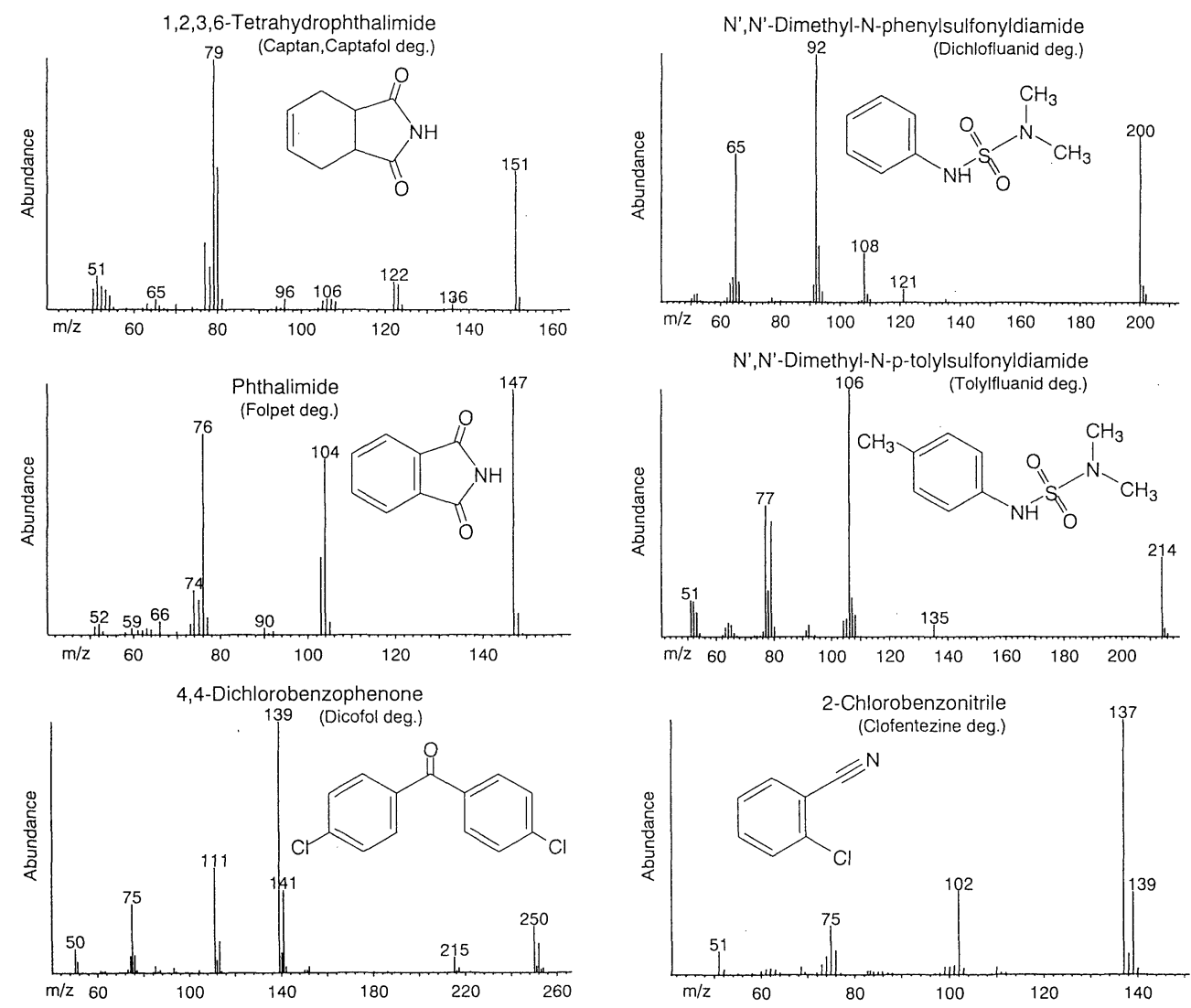

Fig. 1. Mass spectra and structural formulas of pesticide degradation products

shown in Scheme 1. Parent pesticides and degradation products were quantified by $\mathrm{GC} / \mathrm{MS}$.

\section{Degradation at GC injection}

The cleaned-up sample solutions of cabbage, pumpkin, spinach, brown rice and kiwi fruit were used as matrix modifiers. They were dried under an $\mathrm{N}_{2}$ stream, and dissolved in the same volume of mixed standard solution (captan, folpet, dichlofluanid, tolylfluanid, demeton-Smethyl and isofenphos) or captafol solution (1 $\mu \mathrm{g} / \mathrm{mL}$ in $n$-hexane-acetone $(4: 1))$. The modified standard solution was injected into the GC/ MS and the quantities of parent pesticides and their degradation products were compared with those in the standard solution free from matrices.

\section{Results and Discussion}

1. Application of multiresidue method to degradation products

$\mathrm{N}$-Trihalomethylthio fungicides release a tri- halomethylthio group by chemical reaction with thiol groups (-SH) in plant matrices ${ }^{8}$. Dicofol is unstable in acetone solution ${ }^{9)}$ and clofentezine is easily photodegraded ${ }^{2}$. Fig. 1 showed the structural formulas of these degradation products and mass spectra obtained from GC/ MS of their standard solutions.

These degradation products and sulfone or oxon analogues of organophosphorus insecticides which are produced both during analysis and in the plant itself, were added to 3 kinds of agricultural products (brown rice, lemon and spinach) and recovered by the reported multiresidue screening methods ${ }^{7}$. The recoveries were 73.9-129.4\% except for degradation products of captan, captafol and folpet in lemon, owing to interfering peaks (Table 1). These degradation products and metabolites could thus be analyzed simultaneously with their parent pesticides.

2. Pesticide degradation in the presence of plant 
Table 1. Recoveries of Metabolites of Pesticides Added to Agricultural Products

\begin{tabular}{|c|c|c|c|}
\hline \multirow{2}{*}{ Pesticide } & \multicolumn{3}{|c|}{ Recovery (\%, Mean士S.D., $n=3)$} \\
\hline & Brown rice & Lemon & Spinach \\
\hline 1,2,3,6-Tetrahydrophthalimide & $115.3 \pm 4.3$ & - & $112.1 \pm 4.3$ \\
\hline Phthalimide & $89.7 \pm 4.7$ & - & $96.7 \pm 0.8$ \\
\hline$N^{\prime}, N^{\prime}$-Dimethyl- $N$-phenylsulfonyldiamide & $117.8 \pm 2.6$ & $116.2 \pm 6.5$ & $117.8 \pm 0.8$ \\
\hline$N^{\prime}, N^{\prime}$-Dimethyl- $N$-p-tolylsulfonyldiamide & $97.5 \pm 5.0$ & $94.1 \pm 3.1$ & $100.8 \pm 1.5$ \\
\hline $4,4^{\prime}$-Dichlorobenzophenone & $101.4 \pm 2.9$ & $125.2 \pm 3.4$ & $105.6 \pm 2.7$ \\
\hline 2-Chlorobenzonitrile & $103.7 \pm 5.1$ & $113.7 \pm 14.0$ & $91.7 \pm 5.8$ \\
\hline Demeton-S-methylsulfone & $90.7 \pm 3.1$ & $73.9 \pm 5.6$ & $78.3 \pm 2.8$ \\
\hline Diazinon oxon & $95.4 \pm 5.1$ & $114.6 \pm 6.7$ & $94.2 \pm 2.1$ \\
\hline Parathionmethyl oxon & $123.8 \pm 4.5$ & $98.8 \pm 5.6$ & $112.7 \pm 6.0$ \\
\hline Fenitrothion oxon & $122.5 \pm 6.9$ & $110.9 \pm 2.9$ & $112.1 \pm 1.4$ \\
\hline Malathion oxon & $104.9 \pm 4.8$ & $99.3 \pm 7.4$ & $97.1 \pm 2.3$ \\
\hline Parathion oxon & $107.7 \pm 3.2$ & $104.3 \pm 13.3$ & $110.5 \pm 2.1$ \\
\hline Isofenphos oxon & $103.1 \pm 6.3$ & $109.5 \pm 10.3$ & $105.1 \pm 4.6$ \\
\hline Prothiofos oxon & $95.1 \pm 4.1$ & $95.6 \pm 3.1$ & $97.8 \pm 1.7$ \\
\hline Isoxathion oxon & $117.5 \pm 9.9$ & $129.4 \pm 9.5$ & $114.2 \pm 2.9$ \\
\hline EPN oxon & $101.4 \pm 3.6$ & $76.2 \pm 4.9$ & $99.1 \pm 5.2$ \\
\hline
\end{tabular}

\section{matrices}

We investigated the degradation ratios of 5 $N$-trihalomethylthio fungicides (captan, captafol, folpet, diclofluanid, tolylfluanid) and the alteration ratios of demeton-S-methyl to its sulfone analogue and isofenphos to its oxon analogue in the presence of cabbage, pumpkin, spinach, brown rice and kiwi fruit.

Gas chromatograms of standard solutions are shown in Fig. 2. The general tendency was observed that the degradation products of $N$ trihalomethylthio fungicides generated during GC injection were the same as those formed during sample preparation. Stained insert liners and columns in the GC system greatly affect the formation of degradation products ${ }^{10)}$. In GC using clean apparatus, degradation of components of a standard solution was almost negligible.

The following recoveries and degradation ratios were observed during sample preparation and $\mathrm{GC}$ injection.

(1) Captan, captafol, folpet, diclofluanid and tolylfluanid

Recoveries and degradation ratios of the parent pesticides are shown in Table 2 . When these products were made up to a volume of 25 $\mathrm{mL}$ with purified water, all pesticides were recovered as the parent pesticides. In the case of cabbage, the parent pesticides disappeared com-

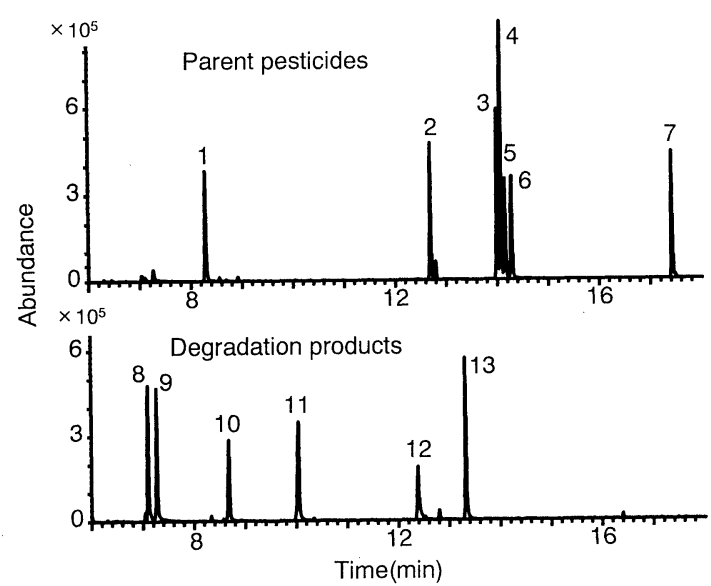

Fig. 2. Total ion chromatograms of pesticides and their degradation products prepared at $1 \mu \mathrm{g} / \mathrm{mL}$ in $n$-hexane-acetone $(4: 1)$ standard solution

1: Demeton-S-methyl, 2: Dichlofluanid, 3: Tolylfluanid, 4: Isofenphos, 5: Captan, 6: Folpet, 7: Captafol, 8: Phthalimide, 9: 1,2,3,6-Tetrahydrophthalimide, 10: $N^{\prime}, N^{\prime}$ Dimethyl- $N$-phenylsulfonyldiamide, $11: N^{\prime}$, $N^{\prime}$-Dimethyl- $N$-p-tolylsulfonyldiamide, 12 : Demeton-S-methylsulfone, 13: Isofenphos oxon

pletely and more than $80 \%$ were recovered as degradation products. In the case of pumpkin, $39-81 \%$ of pesticides were recovered as degra- 


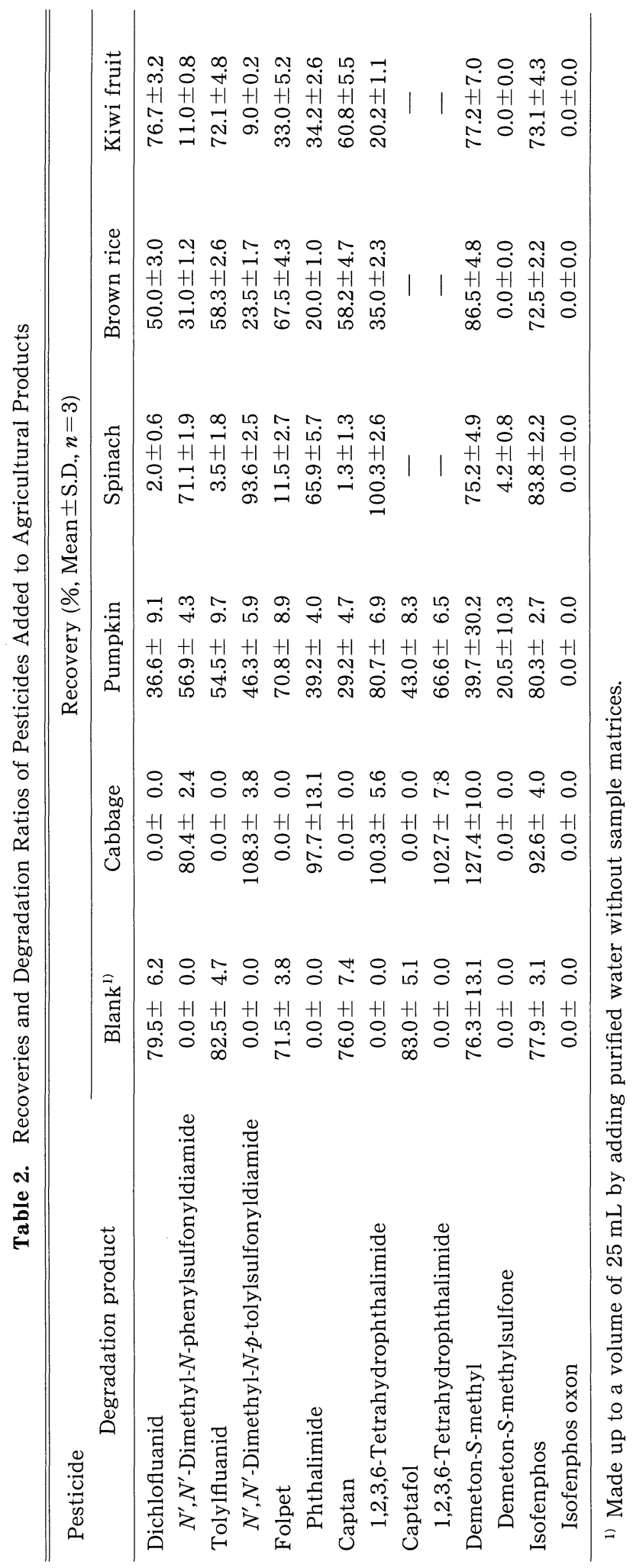


Table 3. Recoveries and Degradation Ratios of Pesticides during GC Injection with Sample Extracts

\begin{tabular}{lrrrrr}
\hline \multirow{2}{*}{ Pesticide } & \multicolumn{3}{c}{ Recovery (\%) } \\
\cline { 2 - 5 } \multicolumn{1}{c}{ Degradation product } & Cabbage & Pumpkin & Spinach & Brown rice & Kiwi fruit \\
\hline Dichlofluanid & 73.3 & 105.2 & 113.0 & 85.3 & 79.9 \\
$N^{\prime}, N^{\prime}$-Dimethyl- $N$-phenylsulfonyldiamide & 20.7 & 0.0 & 0.0 & 0.0 & 7.4 \\
Tolylfluanid & 73.8 & 101.1 & 105.8 & 83.1 & 73.1 \\
$N^{\prime}, N^{\prime}$-Dimethyl- $N$ - $p$-tolylsulfonyldiamide & 24.2 & 0.0 & 0.0 & 0.0 & 5.5 \\
Folpet & 81.9 & 114.4 & 104.6 & 96.9 & 45.2 \\
Phthalimide & 18.8 & 0.0 & 0.0 & 0.0 & 24.2 \\
Captan & 72.4 & 105.4 & 100.3 & 114.5 & 98.1 \\
1,2,3,6-Tetrahydrophthalimide & 22.9 & 8.3 & 0.0 & 0.0 & 9.3 \\
Captafol & 64.1 & 98.1 & 89.1 & 120.5 & 23.6 \\
1,2,3,6-Tetrahydrophthalimide & 36.1 & 16.1 & 28.2 & 0.0 & 52.1 \\
Demeton- $S$-methyl & 131.4 & 117.5 & 111.0 & 103.1 & 105.4 \\
Demeton-S-methylsulfone & 0.0 & 0.0 & 0.0 & 0.0 & 0.0 \\
Isofenphos & 106.8 & 101.3 & 96.4 & 83.5 & 81.6 \\
Isofenphos oxon & 0.0 & 0.0 & 0.0 & 0.0 & 0.0 \\
\hline
\end{tabular}

dation products and total recoveries of parent pesticides and degradation products were 94$110 \%$. Recoveries as degradation products were 66-100\% for spinach, $20-35 \%$ for brown rice, and $9-34 \%$ for kiwi fruit. Total recoveries were 73-102\% except for folpet added to kiwi fruit (67\%). Thus, disappeared pesticides could be detected as degradation products.

It was reported that captan, captafol, diclofluanid and tolylfluanid added to cabbage and pumpkin completely disappear immediately after homogenization*1, ${ }^{*}$. But in this study, samples were homogenized with acetonitrile, and the parent pesticides in pumpkin were not completely lost.

Pesticides were also supposed to be degraded during GC injection owing to the coexistence of plant ingredients ${ }^{10}$. Pesticides added to the cleaned-up extracts from agricultural products were compared by GC/MS analysis with standard solutions (Table 3). Degradation ratios of $N$-trihalomethylthio fungicides were $18-36 \%$ with cabbage extracts, and 5-52\% with kiwi fruit extracts. Captafol was the most degradable, and the degradation ratios were $16 \%$ with pumpkin extracts and $28 \%$ with spinach extracts, although no degradation products were detected with brown rice extracts.

From these results, the alterations to degradation products shown in Table 2 were considered to have been caused mainly during the extraction process and partly during GC injection with cabbage and kiwi fruit extracts.

(2) Demeton-S-methyl and isofenphos

The recovery of demeton- $S$-methyl added to cabbage was $127 \%$ owing to interfering peaks and its sulfone analogue was not detected, but in the case of pumpkin, the sulfone analogue was detected and the recoveries varied widely for both demeton-S-methyl and demeton-S-methylsulfone (Table 2). Modification of pesticides to sulfoxide and sulfone analogues during extraction was reported for aldicarb and ethiofencarb*3. For demeton-S-methyl, its sulfoxide analogue, which is an intermediate product in the formation of the sulfone analogue, was expected to be generated during extraction. In the case of spinach, a small amount of demeton-Smethyl was converted to its sulfone analogue. But demeton-S-methyl was not oxidized to its sulfone analogue during GC injection with any sample extract (Table 3).

Isofenphos added to 5 kinds of agricultural products was not changed to its oxon analogue during sample preparation and GC injection.

\section{Pesticide residue monitoring}

The degradation products of $N$-trihalomethylthio fungicides generated during residue analysis were detected quantitatively with the multiresidue screening method. In F.Y. 1997 151 (89 domestic and 62 imported) agricultural products were analyzed. They included $12 \mathrm{ce}$ reals, 6 beans, 66 vegetables and 67 fruits. Captan and its degradation product were detect- 
Table 4. Pesticide Residues Found in Agricultural Products

\begin{tabular}{clcc}
\hline \hline $\begin{array}{c}\text { Sample } \\
\text { (producing district) }\end{array}$ & \multicolumn{1}{c}{ Pesticide } & $\begin{array}{c}\text { Residue } \\
(\mathrm{ppm})\end{array}$ & $\begin{array}{c}\text { MRL } \\
(\mathrm{ppm})\end{array}$ \\
\hline Apple & Captan & 0.10 & $5.0^{2)}$ \\
(Nagano pref.) & 1,2,3,6-Tetrahydrophthalimide & 0.06 & \\
Grape & Captan & 0.13 & $5.0^{3)}$ \\
(Chile) & $1,2,3,6$-Tetrahydrophthalimide & 0.11 & \\
Grape & Captan & 0.03 & $5.0^{3)}$ \\
(Chile) & 1,2,3,6-Tetrahydrophthalimide & 0.05 & \\
Tomato & Dichlofluanid & 0.11 & $15^{2)}$ \\
(Miyazaki pref.) & $N^{\prime}, N^{\prime}$-Dimethyl- $N$-phenylsulfonyldiamide & 0.18 & \\
Japanese pear & Dichlofluanid & N.D.4) & $5.0^{2)}$ \\
(Hyogo pref.) & $N^{\prime}, N^{\prime}$-Dimethyl- $N$-phenylsulfonyldiamide & 0.01 & \\
\hline
\end{tabular}

1) Maximum Residue Limit

2) Pesticide Residues Standards under Food Sanitation Law

3) Standards for Withholding Registration of Pesticides under Agricultural Chemicals Regulation Law

4) Less than $0.01 \mathrm{ppm}$

ed in 1 sample of domestic apples and 2 of imported grapes, while dichlofluanid and its degradation product were detected in 1 sample of domestic tomatoes, and the degradation product of dichlofluanid was detected in 1 sample of domestic Japanese pears. Details are shown in Table 4. Parent pesticides and their degradation products were detected simultaneously, except for one sample with a low residue level. In all cases, residue levels were less than the maximum residue limits (MRLs).

\section{Conclusion}

The degradation products of $N$-trihalomethylthio fungicides and oxidized organophosphorus insecticides were determined simultaneously with their parent pesticides by the multiresidue screening method. The reduction of parent pesticides from fortified samples was almost quantitatively matched by the increase of their degradation products. Degradation ratios varied depending on the combination of pesticides and sample matrices.

By including the degradation products in routine analysis, the residue levels of degradable pesticides have been roughly estimated by a simple and rapid screening method. An official method for $N$-trihalomethylthio fungicides, which includes acidification with phosphoric acid or hydrochloric acid, is essential only when these pesticides and degradation products are detected in large quantities with the multiresidue method.

\section{References}

1) Ministry of Health and Welfare of Japan: Bulletin 179 , Sep. 1 (1997).

2) Investigation Group of the Method for Pesticide Residue Analysis ed.: "Saishin Nouyaku no Zanryubunsekihou" (1995) Chuouhoukishuppan, Tokyo.

3) Miyamoto, S. ed.: "Atarashii Nouyaku no Kagaku" p. 137-139 (1993) Hirokawashoten, Tokyo.

4) Tukano, T.: Food Sanitation Research 46, 7-26 (1996).

5) Imai, M.: ibid. 47, 29-39 (1996).

6) Akiyama, Y., Yano, M., Mitsuhashi, T., Takeda, N., Tsuji, M.: J. Food Hyg. Soc. Japan 37, 351362 (1996).

7) Akiyama, Y., Yoshioka, N., Yano, M., Tsuji, M.: Bull. Hyogo Pref. Inst. Publ. Hlth. 31, 117-125 (1996).

8) Tomlin, D. ed.: "The Pesticide Manual" 11 th Ed. (1997) British Crop Protection Council, Farnham.

9) Nemoto, S., Takatsuki, S., Sasaki, K., Toyoda, M.: Bull. Natl. Inst. Health Sci. 115, 86-92 (1997).

10) Tonogai, Y., Tsumura, Y., Nakamura, Y., Matsuki, H., Ito, Y.: Jpn. J. Toxicol. Environ. Health 38, 270-281 (1992). 